\title{
3. IVAN ILITCH, HERMENÊTICA, O PAPEL DO SERVIDOR PÚBLICO JUIZ E A MELANCOLIA NO DIREITO
}

\author{
3. IVAN ILITCH, HERMENEUTICS, THE ROLE OF PUBLIC JUDGE \\ AND THE MELANCHOLY IN LAW
}

\author{
Emerson de Lima Pinto ${ }^{1}$ \\ Vanessa Steigleder Neubauer ${ }^{2}$
}

\begin{abstract}
Resumo: O presente artigo tem como objetivo analisar e compreender por meio da obra literária de Tolstói o papel que um servidor público - o juiz possui na prestação jurisdicional e a compreensão do seu ser junto a um modelo de estado burocrático. O julgar e o papel que a lei quanto ciência ocupa em sua vida e o paralelo que Ilitch traça com seus procedimentos nos tribunais e aquele dispensado pelos médicos frente ao diagnostico de sua doença. Neste processo de reflexão chamamos a atenção para a reforma do Estado e o humanismo de Beccaria como contribuição para o Direito que podem contribuir para um serviço público mais humano e correto.

Palavras-chave: Servidor - Administração- humanismo.
\end{abstract}

\begin{abstract}
This article aims to analyze and understand through the literary works of Tolstoy the role that a public servant - the judge - has in adjudication and understanding of his being next to a model of bureaucratic state. The judge and the role that law and science occupies in your life and the parallel he draws with his Ilitch court procedures and that dispensed by doctors against the diagnosis of their disease. Reflection process we call attention to the reform of the state and the humanism of Beccaria as a contribution to the law that may contribute to a more humane and proper public service.
\end{abstract}

Keywords: Server - Administration- humanism.

\section{INTRODUÇÃO}

A de obra Leon Tolstói “A morte de Ivan Ilitch" descreve a sociedade Russa no século XIX e o papel exercido por um magistrado e sua reflexão sobre sua "vida" enquanto magistrado e homem e, de certa forma a melancolia que desvela face suas decisões ao longo dos anos. De certo modo permeia o texto a compreensão do papel do servidor público juiz e sua relevância na sociedade sua tarefa na regulação da vida dos cidadãos.

\footnotetext{
${ }^{1}$ Doutorando em Filosofia. Mestre em Direito. Advogado, Professor na Unisinos e no Cesuca. E-mail: ersonlp@terra.com.br.

${ }^{2}$ Doutoranda em Filosofia. Mestre em Educação nas Ciênicas. Professora da Universidade de Cruz Alta. Email: neubauer7009@hotmail.com.
} 
Ao desenvolver o artigo pretende-se esclarecer por meio de Ivan Ilitch esclarecer a função do servidor público e sua evolução para sociedade democrática e evolução do serviço público. O controle social, a reforma do Estado e o papel que o juiz exerce na sociedade e o método utilizado em seu julgamento e da produção de diagnostico por parte dos médicos em razão de seu modo de ser formalista objetificante trazidos com frequência na narrativa literária de Tolstói e nos permite realizar aproximações com nossa realidade social.

\section{CONTROLE SOCIAL}

Hoje o movimento é no sentido de dotar a sociedade de uma maior numero de instrumentos de controle social que exerce os objetivos de descentralização do setor administrativa do Estado. O século XIX foi pautado por extraordinária centralização: "seu posto ficara em aberto, mas corria, que no caso de sua morte, provavelmente Alexeyev seria nomeado seu sucessor e Vinnikov ou Shtabel ocupariam o lugar de Alexeyev". A parte final do século XX foi um período de transformações política e econômica, que trouxe avanços nas condições humanas em todos os países industrializados. Em nossa sociedade a forma democrática de Estado prende-se ao Estado de Direito de viés liberal, visto que seus institutos recorrem à gênese do constitucionalismo contemporâneo. O Estado exerce o monopólio formal do poder e da coerção; contudo, não se pode esquecer que o exercício privado do poder é uma realidade nas sociedades e, de modo substantivo, sua microfísica do poder está presente em nossa realidade.

A transformação maior do período que nos traz do século XIX em direção ao século XXI foi a mudança do papel do Estado: que passou de tradicional para o provedor direto do progresso social e econômico, para uma nova tarefa onde passa a ampliar um ambiente propício onde a sociedade civil e o setor privado andam estimulados pelo Estado em direção ao desenvolvimento.

\section{HISTÓRIA}

O caminho de formação e desenvolvimento do Estado brasileiro teve inicio no gênese no ambiente colonial, onde se verifica relação tutelar entre o Estado e a nação. Já nos anos 30 se deu, no Brasil, o nascimento do Estado Burocrático, centralizador e intervencionista e, de uma elite empresarial dependente de autorizações, proteções e favores oficiais. Esse novo perfil de Estado nasce em cenário de aceleração da industrialização brasileira, adquirindo tarefa que permite intervir no setor produtivo de bens e serviços. O Estado Burocrático surge para superar o "patrimonialismo" porém dava lugar ao 
"clientelismo": "Vou tentar conseguir a transferência de Kalugo para meu cunhado! pensou Fiodr Ivanovich. "Minha mulher vai adorar e não vai poder dizer que eu nunca faço nada pelos parentes dela".

O cenário era bem diferente da Rússia Czarista na obra de Tolstói onde o Estado guardava elementos de um absolutismo que era inicialmente permeado por uma compreensão liberal que adveio da narrativa de Ivan Ilictch. Poderes muito concentrados, exagerada burocratização, nepotismo, com excesso de funções de confiança e desmedido controle político fizeram parte do Estado Burocrático de matriz absolutista.

No mundo de hoje o modelo de "Estado tridimensional" (econômico, social e administrativo), onde ocorria à intervenção estatal na economia, procura garantir o pleno emprego e atuar em setores considerados estratégicos para o desenvolvimento nacional. Essa concepção de Estado tem como objetivo a produção de políticas públicas na área social. O Estado deve se adaptar/resistir com altivez às tendências globais e ser visto como meio e não um fim em si mesmo; amparo ao cidadão que encontra nele respaldo para sua realização de direitos, condutor de um Estado provedor e redutor de desigualdades.

\section{O DEVIDO PODER DO ESTADO E SERVIDOR PÚBLICO}

A governabilidade é entendida como o espaço de autoridade econômica, política e administrativa para conduzir as ações de um país em todos os níveis. Di Pietro alerta para a necessidade de adotar outra terminologia mais ampla que "servidor público" para designar as pessoas que exercem função administrativa, existindo ou não vínculo empregatício. Nesse sentido, os doutrinadores utilizam a expressão "agentes públicos". A Constituição Federal de 1988 demonstra a existência de quatro categorias de agentes públicos, quais sejam, agentes políticos, servidores públicos, militares e particulares em colaboração com o Poder Público. Em Ivan Ilitch se encontra figura do agente político, não obstante algumas divergências. Di Pietro apoia o posicionamento de Bandeira de Mello:

"agentes políticos são os titulares dos cargos estruturais à organização política do País, ou seja, são os ocupantes dos cargos que compõem o arcabouço constitucional do Estado e, portanto, o esquema fundamental do poder. Sua função é a de formadores da vontade superior do Estado". ${ }^{1}$ 
Nesta seara são agentes políticos vistos na Constituição, entre os atuais, o presidente, governadores, prefeitos e auxiliares imediatos (Ministros e Secretários), os senadores, deputados e vereadores. A função política diz respeito às atividades de direção e as legislativas. O judiciário de Ivan Ilitch possui participação quase nula uma vez que sua função é restrita à atividade jurisdicional, sem a possibilidade de influenciar a ação política do governo, senão pelo controle a posteriori.

Portanto, não é suficiente que o exercício de atribuições constitucionais para que se entenda como agente político o desempenha, mas que exerçam atividades típicas de governo e mandato, para o qual tenham sido eleitos, exceto nos casos de ministros e secretários, que são de livre nomeação do Chefe do Executivo. Neste contexto há uma tendência hegemônica a considerar membros do Ministério Público e Magistratura como agentes políticos, pois, aos membros da magistratura é válida tal compreensão visto que se tenha como sentido a sua atuação é política, não significando que participem da administração do governo e que suas decisões são fundadas em critérios de conveniência e oportunidade, mas que exercem parcela da de soberania do Estado. Não olvidemos o fato de que o vínculo com o poder público é de natureza estatuária conduzido pela Lei Orgânica da Magistratura.

Na gestão contemporânea do Estado e do serviço publico se torna necessário desenvolver a "governabilidade" onde imperam três questões distintas: a primeira delas diz respeito ao patrimônio líquido (redução da pobreza); a segunda envolve a eficiência econômica deste Estado (desigualdades advêm de processos de desenvolvimento problemáticos); e, por fim, o terceiro tópico diz respeito à sustentabilidade, que é um fator determinante para o crescimento econômico em longo prazo (deslocando seu eixo do setor produtivo para a sociedade).

\section{ESTADO BUROCRÁTICO E AS FORMAS DE ADMINISTRAÇÃO}

A construção de uma Nação se faz através de um projeto concentrado em produção, desenvolvimento econômico e investimento social estabilizando e assegurando o desenvolvimento sustentado da economia que promoverá a correção das desigualdades sociais e regionais onde é necessário fortalecer o Estado-nacional para ser eficaz sua ação reguladora. As reformas da administração exigem uma carga infraconstitucional de regulamentação para que possam ser efetivadas e, em muitos locais, a alteração da Constituição ou de outras normas. Nesse sentido o direito administrativo tem apresentado um forte componente comunitário, isto é, ocorre na medida em que o Direito Administrativo é o Estado em ação. Os limites impostos aos gestores públicos, bem como, seu impositivo agir são delineados com maior concretude nessa seara do que é afirmado no Direito Constitucional. O Direito Administrativo foi influenciado pelo neoliberalismo devastador e "autopoético" que impulsiona as Reformas do Estado que se moldam ao modelo neoliberal, bem como, 
uma pálida integração de mercados como a que se propõe o Mercosul que geraram um intensivo processo de privatizações (Brasil) por um lado, e as Pós-privatizações de outro (Argentina, Chile, México).

Sobre o que estava acontecendo com o Direito Administrativo diante do neoliberal processo de Reforma do Estado com a fragilização do Direito Constitucional que antecipa a falência ou morte do Direito Administrativo foi interrompido no Brasil nos inicio do século XXI. A ampliação, pulverização e multiplicação das fontes produtoras de normatividade jurídica vêm se tornando mais complexa e plural. A discussão em torno do direito aplicável a cada situação concreta da vida administrativa tornase vulnerável diante da constante transformação do Estado a partir nas reformas sugeridas pelas instituições financeiras internacionais. A globalização tem instigado uma mundialização sentidos e busca (consciente-inconscientemente) construir uma nova gramatica da cultura contemporânea onde às subjetividades passam a ter muito valor e ao mesmo tempo nenhum. O local e o global aparecem desconectados ao mesmo tempo em que aspiramos por uma sociedade humana e o pensamento helênico pode proporcionar um refluir de sua cultura (Física, Ética e Filosófica).

Depois de passada as fases de Administração Patrimonialista, que possuía forma de administrar, o Estado e seus agentes possuem um status superior. O modelo de gestão causava confusão entre os cargos públicos e o grau de parentesco e afinidades entre os nobres e outros agentes do governo, uma herança típica do injusto modelo administrativo das antigas monarquias, como na Russa de Ivan Ilitch que poderia se dar ao disparate de: "E permitia-se faze-lo era justamente porque podia, no momento que quisesse, reassumir o tom puramente oficial e abandonar a atitude humana" A administração burocrática que propulsionou o capitalismo e a democracia diante da necessidade de se lutar contra o nepotismo e a corrupção que eram heranças presentes na administração patrimonialista sucederam a ideia do Estado servil, pois suas bases se constituam de vertical hierarquia funcional a partir da profissionalização na forma de eleger agentes e servidores, apresentando rigidez nos processos de admissão de pessoal.

De certo modo, uma Administração de perfil Gerencial é a que mais se identifica com controle social e tem possibilidades de aprofundamento republicano. Nasceu diante da expansão progressiva das funções econômicas e sociais do Estado, do desenvolvimento tecnológico e da globalização da economia. A ampliação, pulverização e multiplicação das fontes produtoras de normatividade jurídica veem se tornando mais complexa e plural. Neste modelo de gestão tende a ser cada vez mais seguido pelo mundo contemporâneo, uma vez que o Estado focaliza sua atenção sobre o cidadão, resgatando a função da esfera pública como instrumento do exercício da cidadania participativa.

\section{REFORMA ADMINISTRATIVA E NOVO PAPEL DO ESTADO E o servidor público em}




\section{estado democrático e participativo E O JUIZ}

Em Ivan Ilitch se verifica forte influência kantiana que quando procurava decidir em seus julgamentos buscava se observar aos fatos e as normas despindo-se de sentimentos morais, de modo a demonstrar o fato de que a razão pura é prática por si mesma, logo ela funda a lei que conforma a moralidade, na razão kantiana emerge as leis práticas que conduzem a vontade. Para o autor as leis práticas são princípios práticos objetivos, regras válidas para todo ser racional. Desta feita, elas se distinguem das máximas que se formam em espécies de princípios práticos subjetivos (válidas para sua própria vontade do sujeito).

A democratização do Estado é uma consequência da reforma do Estado, e evidentemente, a salvaguarda do exercício da cidadania. A relevância da Reforma Administrativa está residindo nas consequências desta reestruturação para a nação, como a ação do Estado na economia, à redução do déficit e a melhoria na eficiência dos serviços públicos e prováveis alterações nos mecanismos de controle dos recursos públicos e, exige, transformações no ordenamento jurídico, nos regulamentos e nas técnicas e formas de trabalho da administração pública, com o objetivo de melhorar a qualidade e a eficiência dos serviços prestados à sociedade tendo por fim o cidadão. Neste processo é necessária à clareza quanto à direção pública esperada de modo a incorporar um principio de democracia, que prevê inclusão de servidores efetivos, quanto dos agentes políticos. A reforma de um Estado deve criar condições para programar o desenvolvimento econômico-social, fundado nos valores da democracia e participação social.

\section{HUMANISMO E O JUIZ LITERÁRIO DO SÉCULO XIX}

Em Ivan Ilitch se percebe uma reflexão agora retrospectiva em razão de seu modo de julgar dogmático e atrelado à lei. De certo modo, felizmente, Beccaria havia lançado as bases de uma justiça penal mais humana e teve séculos após sua morte a viabilização de alguns de seus fundamentos na sociedade. Imerso numa cultura burocrática Ilitch não poderia ser considerado humanista e, tão pouco, despótico. As lições que servem à contemporaneidade decorrem de um aprendizado autoritário de sociedades como a da Rússia. A maior parte das leis penais não foi senão privilégio: "as penas devem ser adequadas a mal social causado pelo delito. A pena não deve cair sobre o inocente, obrigado a cometer delitos por necessidade e desespero".

De certo modo, o magistrado Ivan Ilitch seguia os preceitos de Beccaria na medida em que os julgadores dos crimes na compreensão não poderiam ter o direito de interpretar as leis penais pela própria razão de não serem legisladores. Em Beccaria os juízes recebem lei da sociedade viva, sendo 
depositários da vontade geral. A interpretação da norma segundo Beccaria teria que obedecer ao silogismo formal perfeito de modo à dogmaticamente desprover a lei de sua moralidade adotando uma leitura tecnicista-formalista: "La chegando, caia imediatamente na sua rotina de trabalho e preparavase para lidar com petições, processos e as sessões publicas e administrativas. Em tudo isso, fazia-se necessário excluir dali tudo o que contivesse vida dentro de si - o que sempre perturba o andamento normal das coisas oficiais”. O juiz não poderá ser submetido a fazer qualquer tipo de raciocínio a mais do que o tipo penal ordena. "Não há nada mais perigoso do que o axioma comum de que é necessário consultar o espírito da lei". A vagueza das leis sempre instituiu um problema relevante que deverá ser equacionado, a linguagem das normas deve ser compreensível e não tão solene, na qual o advogado torna-se um oráculo de uma verdade a ser (re)velada e, tal paralelo pode ser estabelecido na "Morte de Ivan Ilitch" quando Tolstói destaca a técnica utilizada pelos médicos em seus diagnósticos e a adotada por Ilitch nos Tribunais ao julgar (intérpretes das leis). Não se pode ignorar a notável contribuição do iluminismo que se constitui em elemento essencial do espírito da cultura da ocidental.

O celebre especialista despediu-se com a expressão seria e solidaria, mas pouco animadora. A tímida pergunta feita por Ivan Ilitch com os olhos cheios de medo e esperança, sobre se havia alguma chance de recuperação, respondeu que não podia garantir, mas que certamente havia uma possibilidade o olhar de esperança com que Ivan Ilitch observava o medico ir embora era tão patético que ao velo, quando passava pelo escritório para fazer o pagamento, Praskovya começou a chorar. .

Beccaria compreendia que era contrário aos fins da própria sociedade e (in)segurança pessoal causada pela prisão arbitrária realizada nos séculos XVII e XVIII. Naquele período diversos países adotavam tal procedimento. Contudo, posteriormente tal princípio da (legalidade) foi formulado por Feuerbach: "nulla poena sine lege”, ou melhor, "não há crime sem lei anterior que o defina. Não há pena sem previa cominação legal”. O iluminismo legou a humanidade, o que pode ser verificado através do art. $8^{\circ}$ da Declaração dos Direitos do Homem e do Cidadão, proclamada durante a Revolução Francesa de 1789 antecipadora da consolidação escrita dos direitos humanos. A declaração se fundava em formas positivas que adotava o direito natural conforme as tendências racionalistas do Século XVIII e XIX. Assim sendo, podemos afirmar que a hermenêutica metodológica, de modo geral, contenta-se apenas com o respondido, relegando ao âmbito do sem-sentido o perguntar o que torna o convertido ao plano é tido e reconhecido como válido pela hermenêutica metodológica. O modelo clássico de hermenêutica metodológica foi desenvolvido como condições e pressupostos da arte de compreender por Schleiermacher e, a sua hermenêutica necessitaria explicar o processo mesmo de compreender. Desse modo não deveria se prender apenas à "atividade de traduzir passagens difíceis em língua estrangeira", mas precisaria ser desenvolvida segundo o pressuposto de uma "familiaridade com o objeto e a língua", pois ao interpretar compreendemos. Essa dimensão converte-se, posteriormente, 
em um dos princípios da hermenêutica filosófica. (RHODEN, 2009, p. 75)

O compreender, conforme Schleiermacher fundamenta-se em dois momentos: "compreender o falado como algo que provém da língua e compreendê-la como um fato naquele que pensa", isto é, "todo falar pressupõe urna dada língua" que "se desenvolve pela fala" e "cada instância do falar se baseia em um pensar anterior"; disso concluiu que "todo ser humano é, por um lado, um local no qual uma dada língua adquire forma de maneira peculiar, só se podendo compreender sua fala a partir da totalidade da língua". Aqui encontramos alguns aspectos pressupostos do método interpretativo, isto é, a relação entre a parte e o todo, a linguagem como língua no sentido de fatigue e como forma peculiar de acontecer no sentido de parole.

O princípio da legalidade penal implica na impossibilidade da punição (sanção) daqueles fatos que através da lei, na sejam estabelecidos como crime (tipicidade). Mesmo que esse fato praticado seja ofensiva à moral (compreendida como senso comum social), antissocial ou danoso, "haverá possibilidade de se punir o autor, sendo irrelevante as circunstâncias de entrar em vigor, posteriormente uma lei que o preveja como crime”. Desta forma evita-se a discrição vaga e indeterminada que impossibilita estabelecer qual a abrangência do preceito primário da lei penal e permite com isso o arbítrio do julgador como podemos verificar na postura jutisdicional de Ivan Ilitch.

Em sua obra "Elogio a teoria" Gadamer nos guia na direção de que após verificar seu deslocamento e evoluir no tempo evidencia-se uma espécie de consciência formada, contudo, não é admissível o fato de que se pode formar uma consciência estruturada "pela ciência" e "para a ciência" visto que tão somente de ser uma consciência humanamente formada, que aprendeu a implicar no seu pensamento os pontos de vista do outro e a buscar o consenso sobre o que é comum e, de certa forma, o autor alemão demonstra sua preocupação com os rumos observados por esta natureza de saber do ser humano como forma de autoconsciência o que instiga-nos cada vez mais a pensar nossa práxis que deve indicar o modo como desenvolvemos nossa caminhada em direção à edificação de nosso destino (construído).

\section{CONSIDERAÇÕES FINAIS:}

Neste artigo se verificou diversos temas que fazem parte da historia da democracia apesar de não ser de conhecimento de todo cidadão, são assuntos de importância na vida da população por meio de uma narrativa de um magistrado que dedica a sua vida ao trabalho tendo como condição de vida uma cisão afetiva com sua família. A técnica desprovida de eticidade é sistematicamente trazida no ambiente melancólico que cerca a vida e as relações de Ivan Ilitch na soturna sociedade czarista do século XVIII. 
A estrutura formal-objetificante de seu processo decisório frente a concepções dominantes no direito positivismo-normativista apartado de uma eticidade dão conta de parte da melancolia no qual alguns magistrados podem ser encontrados na contemporaneidade. Talvez não com a pantanosa realidade de Ivan Ilitch de Tolstói, mas, em condições similares em aspectos de sua mundaneidade.

A transformação do perfil do Estado do século XVIII ao XXI afeta a estrutura do EstadoAdministração e Estado-Juiz de modo significativo no que se refere à organização, modo de ser e atribuições no ocidente democrático e republicano, entretanto, quanto ao processo decisório e o ambiente que cerca aos magistrados envolvem um conjunto de elementos psicossociais que influenciam no ser produtor de decisões que afetam não apenas o circulo de relações, mas, também, a sociedade em razão do poder-dever no qual estão imersos. No desenvolvimento da democracia (re)pensar o Estado como aparelho burocrático distanciado da sociedade que dota indivíduos de condições de isolamento laborativamente dos mesmos e, de certa forma, resulta no aperfeiçoamento do Estado Democrático e, nesse sentido, os vícios demonstrados na obra de Tolstói indicam caminho a ser superado na sociedade organizada por meio de um discurso técnico-cientifico entificante. Em síntese, sobre o papel do servidor público juiz é de suma importância para se entenderem como esses agentes são escolhidos, quais são os princípios que os regem e como são seus verdadeiros papéis debatidos em razão da práxis, que busque evitar descompromisso com a moralidade na prática dos servidores publico tendo em vista a possibilidade de se ocultar no escudo da legalidade necessária a prestação jurisdicional adequada.

\section{REFERÊNCIAS}

BECCARIA, Cesare. Dos Delitos e das Penas. São Paulo: Hemus, 1983.

Di Pietro, Maria Sylvia Zanella. Direito administrativo. $20^{\circ}$ edição, São Paulo, 2007.

FOUCAULT, Michel. Microfísica do poder. 11 reimpressão . Editora Graal : Rio de Janeiro, 2005. p. $12-4$.

GADAMER, O Caráter Oculto da Saúde. Vozes. 2011.

GADAMER, Hans-Gerg. A diversidade da Europa. Herança e futuro. (1985) In A herança e o futuro da Europa. Edições 70: Lisboa, 1998.

HÄBERLE, Peter. Libertad, igualdad, fraternidad. 1789 como historia, actualidad y fututo del Estado constitucional. Prólogo de Antônio Lopes Pina. Madrid: Mínima Trotta, 1998.

ROHDEN, Luiz; FLICKINGER, Hans-Georg; ALMEIDA, Custódio Luis Silva de. Hermeneutica Filosofica: nas trilhas de Hans-Georg Gadamer.

Hermenêutica filosófica. São Leopoldo: Editora UNISINOS, 2002. 
Revista Diálogos do Direito

Interfaces da Hermenêutica. Caxias do Sul, RS: EDUCS, 2008.

TOLSTÓI, Leon. A morte de Ivan Ilitch. Porto Alegre: LPM, 2014.

VAZ, Pe. Henrique C. de Lima. Antropologia Filosófica I. São Paulo: Loyola, 1999. p. 86-7.

VAZ, Pe. Henrique C. de Lima. Escrito de Filosofia II: Ética e Cultura. São Paulo: Loyola, 2000

VIEIRA, Oscar Vilhena. Realinhamento Constitucional. In. Direito Global. SUNDFELD, Carlos Ari \& VIEIRA, Oscar Vilhena (Org.)

(Artigo submetido em 01/12/2014 e aceito em 28/12/2014) 